\title{
Polymer microchip impedance spectroscopy through two parallel planar embedded microelectrodes: Understanding the impedance contribution of the surrounding polymer on the measurement accuracy
}

\author{
Mohammed Kechadi ${ }^{\mathrm{a}, \mathrm{b}, \mathrm{c}}$, Jean Gamby a,b,*,1 , Lila Chaal ${ }^{\mathrm{c}}$, Hubert Girault ${ }^{\mathrm{d}}$, \\ Boualem Saidani ${ }^{\mathrm{c}}$, Bernard Tribollet ${ }^{\mathrm{a}, \mathrm{b}}$ \\ a CNRS, Laboratoire Interfaces et Systèmes Electrochimiques, UPR 15, F-75252 Paris, France \\ ${ }^{\mathrm{b}}$ UPMC, LISE UPR 15 CNRS, 4 Place Jussieu, case postale 133, F-75252 Paris, France \\ ' Laboratoire d'Electrochimie, Corrosion et de Valorisation Energétique (LECVE), Faculté de Technologie, Université A. MIRA, Béjaia 06000, Algeria \\ ${ }^{\mathrm{d}}$ Laboratoire d'Electrochimie Physique et Analytique, Ecole Polytechnique Fédérale de Lausanne, Faculté des Sciences de Base, Institut des Sciences et \\ Ingénierie Chimiques, 1015 Lausanne, Switzerland
}

\section{A R T I C L E I N F O}

\section{Article history:}

Received 14 January 2013

Received in revised form 26 April 2013

Accepted 26 April 2013

Available online 7 May 2013

\section{Keywords:}

Microchip

Contact free impedance

Constant-phase element

Polyethylene terephthalate

Photoablation

\begin{abstract}
A B S T R A C T
The present work describes a new methodology for contact free impedance of a solution in a polymer microchip taking into account the role played by the surrounding polymer on the impedance accuracy. Measurements were carried out using a photoablated polyethylene terephthalate (PET) microchannel above two embedded microband electrodes. The impedance diagrams exhibit a loop from high frequencies to medium frequencies $(1 \mathrm{MHz}-100 \mathrm{~Hz})$ and a capacitive behavior at low frequencies $(100-1 \mathrm{~Hz})$. The impedance diagrams were corrected by eliminating from the global microchip response the contribution of the impedance of the PET layer between the two microband electrodes. This operation enables a clear observation of the impedance in the microchannel solution, including the bulk solution contribution and the interfacial capacitance related to the surface roughness of the photoablated microchannel. Models for the impedance of solutions of varying conductivity showed that the capacitance of the polymer-solution interface can be modeled by a constant phase element (CPE) with an exponent of 0.5 . The loop diameter was found to be proportional to the microchannel resistivity, allowing a cell constant around $4.93 \times 10^{5} \mathrm{~m}^{-1}$ in contactless microelectrodes configuration.
\end{abstract}

(C) 2013 Elsevier Ltd. All rights reserved.

\section{Introduction}

The development of miniaturization technology is increasing, due to the well-known advantages and the crucial need for micrometer scale measurements with improved detection sensitivity [1-3]. Hence, micro-total analysis systems ( $\mu$ TAS) are usually designed for a well-defined analytical task [4]. A wide range of detection techniques has been employed in microfluidic devices, such as optical detection, laser induced fluorescence, luminescence, electrochemistry, surface plasmon resonance, and mass-spectroscopy [5-7]. However, electrochemical detection (ECD) offers specific advantages for microfluidic systems due to its

\footnotetext{
* Corresponding author at: CNRS, Laboratoire Interfaces et Systèmes Electrochimiques, UPR 15, F-75252 Paris, France. Tel.: +33 1442736 40; fax: +33144274074

E-mail address: jean.gamby@upmc.fr (J. Gamby).

1 ISE member.
}

small size, portability, low cost, high sensitivity, and high selectivity using a proper choice of detection potential and/or electrode material [8]. An additional advantage of ECD is the simplicity of the instrumentation, resulting in low electrical power requirements for in-field use [9-12]. Electrochemical impedance spectroscopy (EIS) is a sensitive analysis method for biological samples [13-16]. Indeed, the possibility to integrate impedance analysis into existing lab-on-a-chip designs offers great potential to obtain new insights and to achieve a profound understanding of biological processes, which are not accessible through conventional analysis. With this method, the bias of the sensing electrode potential can be controlled, even though some unwanted problems such as bubble generation, microelectrode passivation, and/or contamination can occur. To overcome these limitations, use of electrodes that do not contact electrolyte has been investigated, mainly in capillary electrophoresis with electrical detection. It is interesting to stress that non-contact conductivity measurements using external tubular electrodes all around the capillary was introduced in 1998 by Zemann et al. [17] due to a problem encountered with electrical 


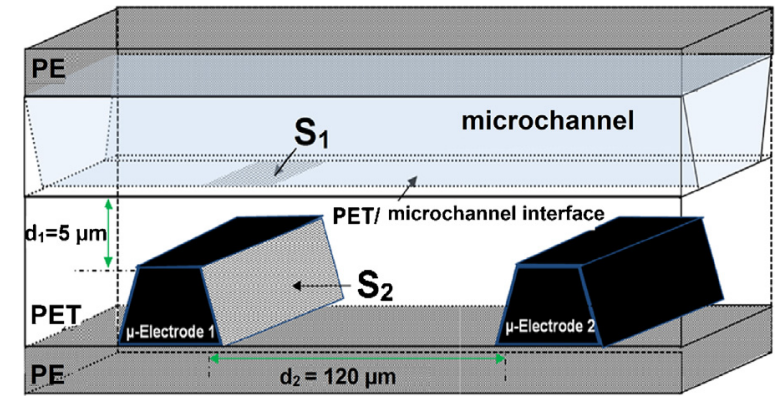

Fig. 1. Schematic representation of PET-microchannel-microelectrodes interface.

coupling between the high voltage applied in the capillary and the conductivity cell detection located at the end-column. However, in the literature, the signal excitation is high $(5-10 \mathrm{~V})$ due to high impedance of silica capillary with pasted electrodes. In this case, the linearity of the system is not maintained during measurement.

The growth of microfluidic technologies with widely varying substrate requirements has led to an increased interest in polymeric materials due to their good bio-chemical performance and low cost. Recently, Gamby et al. [10,13] described microchannels and contact-free microelectrodes using a microfabrication process based on photoablation of polyethylene terephthalate (PET). This process is an attractive alternative to other expensive, laborious, and time-consuming methods for microchannel fabrication such as photolithography approaches. However, when choosing a polymer-based substrate, the properties of the material are critical for both the fabrication process and the successful application of the device. Therefore, we propose in the presented work, a thorough study based on a sensitive non-contact technique in order to understand the physical phenomena taking place within the PET microsystem. Measurements were undertaken of dielectric response to a perturbation of voltage between two microelectrodes embedded in the dielectric polymer. Simulation and experimental results were used throughout the paper to illustrate the effectiveness of such an approach. This approach can be employed to detect any kind of molecule. Further development to identify the type of adsorption that governs the protein-PET system and to a better understanding of the factors that govern this adsorption can be also foreseen.

\section{Experimental}

The microchip device used in this work was described elsewhere $[10,13]$. Some modifications have been made and will be outlined hereafter. The set-up is displayed in Fig. 1. Impedance measurements were carried out through a photoablated polyethylene terephthalate (PET) microchannel having a trapezoidal crosssection shape with a depth of $45 \mu \mathrm{m}$, a top width of $100 \mu \mathrm{m}$ and a length of $1.4 \mathrm{~cm}$. The separation distance between both microchannels was $200 \mu \mathrm{m}$ center to center and $120 \mu \mathrm{m}$ edge to edge. The electrode fabrication was achieved using a carbon ink loaded with gold nanoparticles, thermally laminated at $135^{\circ} \mathrm{C}$ and a pressure of $2 \mathrm{bar}$ by a polyethylene $(10 \mu \mathrm{m}) /$ polyethylene terephthalate $(25 \mu \mathrm{m})(\mathrm{PE} / \mathrm{PET})$ layer. The total thickness of the laminated layer is equal to $35 \mu \mathrm{m}$. The separation distance in the PET band between the two planar microelectrodes and the main microchannel was equal to $5 \mu \mathrm{m}$ and the detection surface area per microelectrode was $80 \mu \mathrm{m} \times 100 \mu \mathrm{m}$.

Electrochemical impedance spectroscopy measurements were performed by applying an AC voltage with constant amplitude $(0.1 \mathrm{~V})$ through the microelectrodes with a frequency ranging from $1 \mathrm{MHz}$ to $1 \mathrm{~Hz}$. The current measured is thus related to the total impedance of the sensor. These measurements were performed

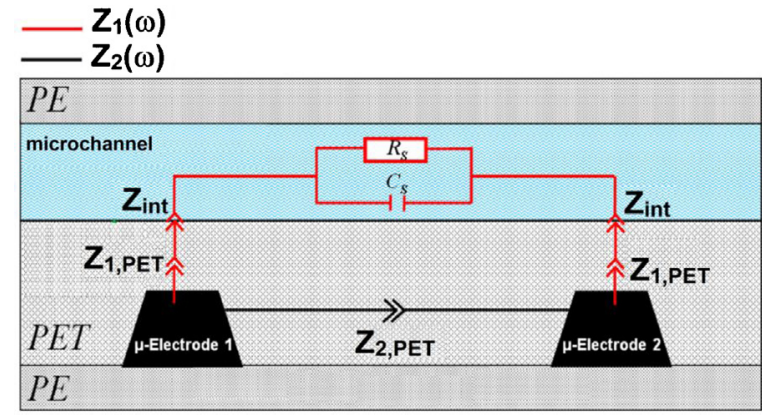

Fig. 2. Representation of the microchip by an equivalent electrical circuit.

using a frequency response analyzer (FRA 1255B, Solartron, UK) together with a dielectric interface 1296 (Solartron, UK) which extends the frequency range from $1 \mathrm{MHz}$ to $10 \mathrm{~Hz}$. Data analysis was performed using the commercial software SMaRT. The effect of $\mathrm{NaCl}$ solutions on the resistance in the microchannel was studied at various concentrations $\left(0-10^{-2} \mathrm{M}\right)$. To analyze these results, a physical model was used as is described in Fig. 2. The data obtained were treated using a home-made software SIMAD which allowed fitting both frequency-dependent analytical expressions and equivalent electrical circuits.

\section{Results and discussion}

The results of impedance measurements between the two band microelectrodes depend on the surface state of the flow channel and on adsorption taking place on the walls of the flow channel. However, in the previous study [10], the impedance between the microelectrodes and the microchannel through the bulk of the PET substrate was not considered since it has been reported that the resistance is large enough that it could be disregarded. Thus, impedance measurements performed here are undertaken on the device when it is empty or filled with a sodium chloride solution in order to reach a better understanding of the PET impedance contribution in the global response.

\subsection{EIS measurements in an empty microchannel}

Polyethylene terephthalate is a dielectric material [18]. Its capacitive behavior between the two microelectrodes can be evaluated using

$C_{2, \mathrm{PET}}=\frac{\varepsilon_{0} \varepsilon_{r} S_{2}}{d_{2}}$

where $C_{2, \mathrm{PET}}$ is the geometric capacity in the PET thickness, $\varepsilon_{0}$ is the vacuum permittivity $\left(8.854 \times 10^{-12} \mathrm{Fm}^{-1}\right), \varepsilon_{r}$ is the relative permittivity of the PET film (3.4), $d_{2}$ is the average distance separation between the two electrode edge to edge $(120 \mu \mathrm{m})$ and $S_{2}$ is the vertical surface of the microelectrodes $\left(2 \times 10^{-7} \mathrm{~m}^{2}\right)$. This derivation gives a value of $4.5 \times 10^{-14} \mathrm{~F}$. Eq. (1) does not take into account the horizontal part of the two microelectrodes shown in Fig. 1.

Impedance measurements in the case of empty microchannel in the frequency range from $1 \mathrm{MHz}$ to $1 \mathrm{~Hz}$ and with $0.1 \mathrm{~V}$ are presented in Fig. 3. The Nyquist diagram shows a capacitive behavior over the entire frequency range, but the representative line is not exactly vertical. It is interesting to stress that the conventional RC circuit is not convenient for modeling impedance response through the dielectric PET layer. The impedance $Z_{2}(\omega)$ between the two microelectrodes for the empty microchannel has a capacitance 

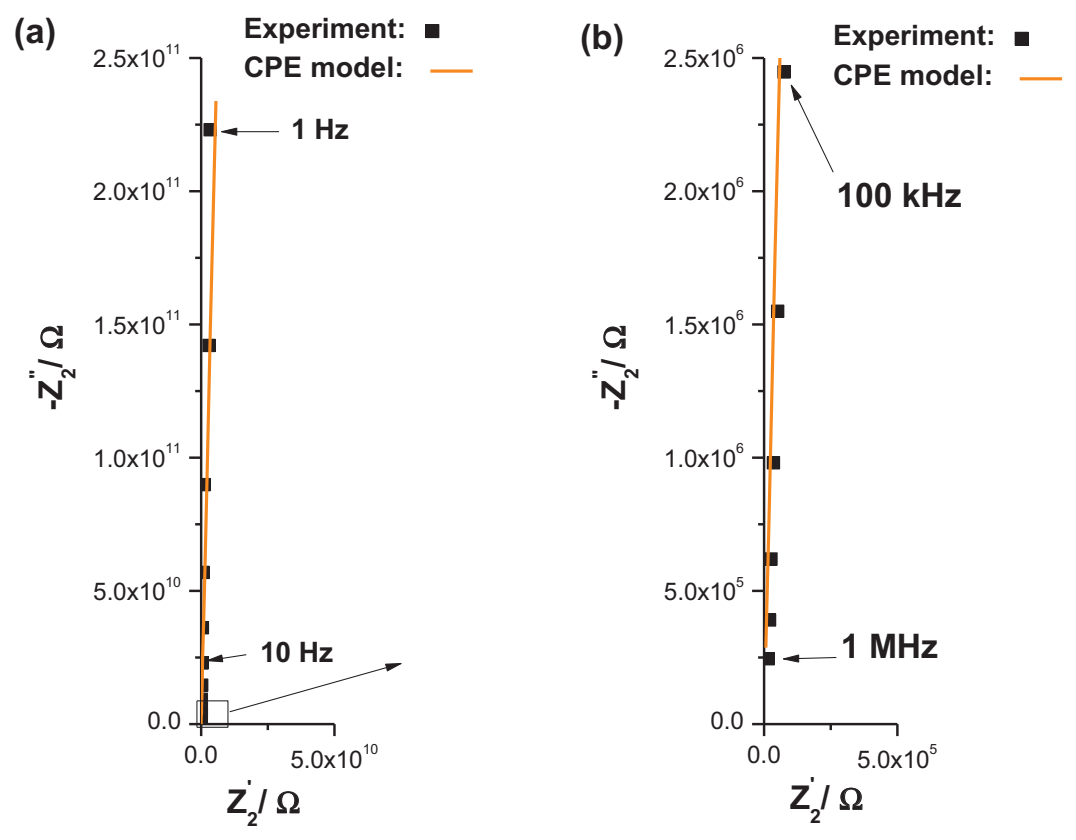

(c)

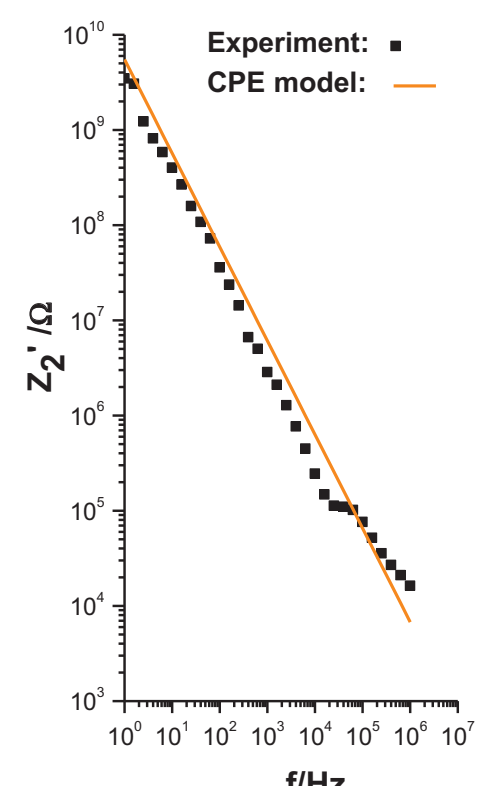

(d)

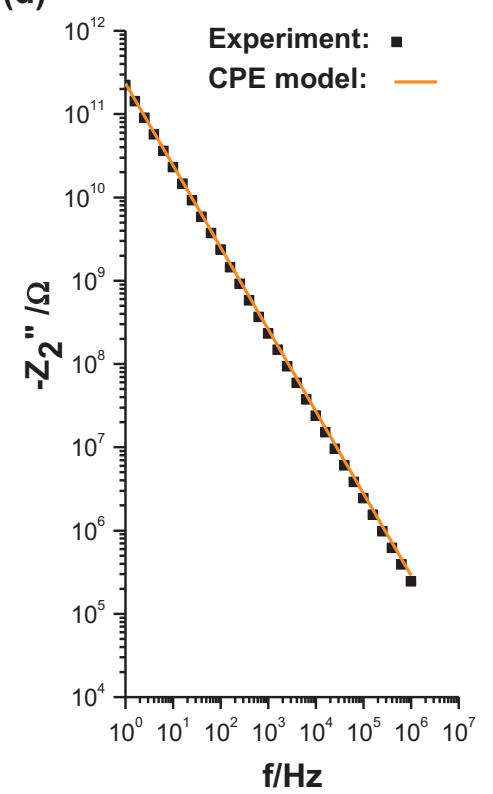

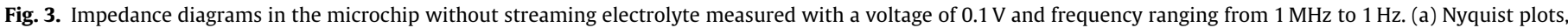
(b) Nyquist plots magnification, (c) real part $v s$ frequency and (d) imaginary part $v s$ frequency.

behavior represented by constant phase element (CPE), defined as

$Z_{2, \mathrm{PET}}(\omega)=\frac{1}{(j \omega)^{\alpha_{2, \mathrm{PET}}} Q_{2, \mathrm{PET}}}$

where $Q_{2, \text { PET }}$ is the CPE constant $\left(\Omega^{-1} s^{\alpha}\right)$ and $\alpha_{2, \text { PET }}$ is the CPE exponent.

As described by Orazem et al. [19], the log-log representation of the imaginary part of impedance $v s$ frequency is suitable for a CPE analysis. The $\alpha_{2, \text { PET }}$ value corresponding to the slope of the curve plotted in Fig. $3 d$ is 0.99 . The extracted value of the CPE element $\left(Q_{2, \text { PET }}\right)$ in the PET thickness of $120 \mu \mathrm{m}$ is estimated to $8.5 \times 10^{-13} \Omega^{-1} \mathrm{~s}^{\alpha}$.

The slight difference in value between the CPE element $Q_{2, \text { PET }}$ and $C_{2, \mathrm{PET}}$ is due to the capacitive effect of the horizontal surface of the microelectrodes as mentioned above. The average value of $0.85 \mathrm{pF}$ value could be considered to be the overall background (or stray) capacitance.

In the following, the impedance $Z_{2, \mathrm{PET}}$ will be determined using Eq. (2) with $\alpha_{2, \mathrm{PET}}=0.99$ and $Q_{2, \mathrm{PET}}=8.5 \times 10^{-13} \Omega^{-1} \mathrm{~s}^{\alpha}$.

From the knowledge for an empty microchannel $Z_{2}(\omega)$, the impedance in the microchannel $\left(Z_{1}(\omega)\right.$ in Fig. 2$)$ can be deduced from the global impedance measurement $Z_{\mathrm{G}}(\omega)$. Then in the 

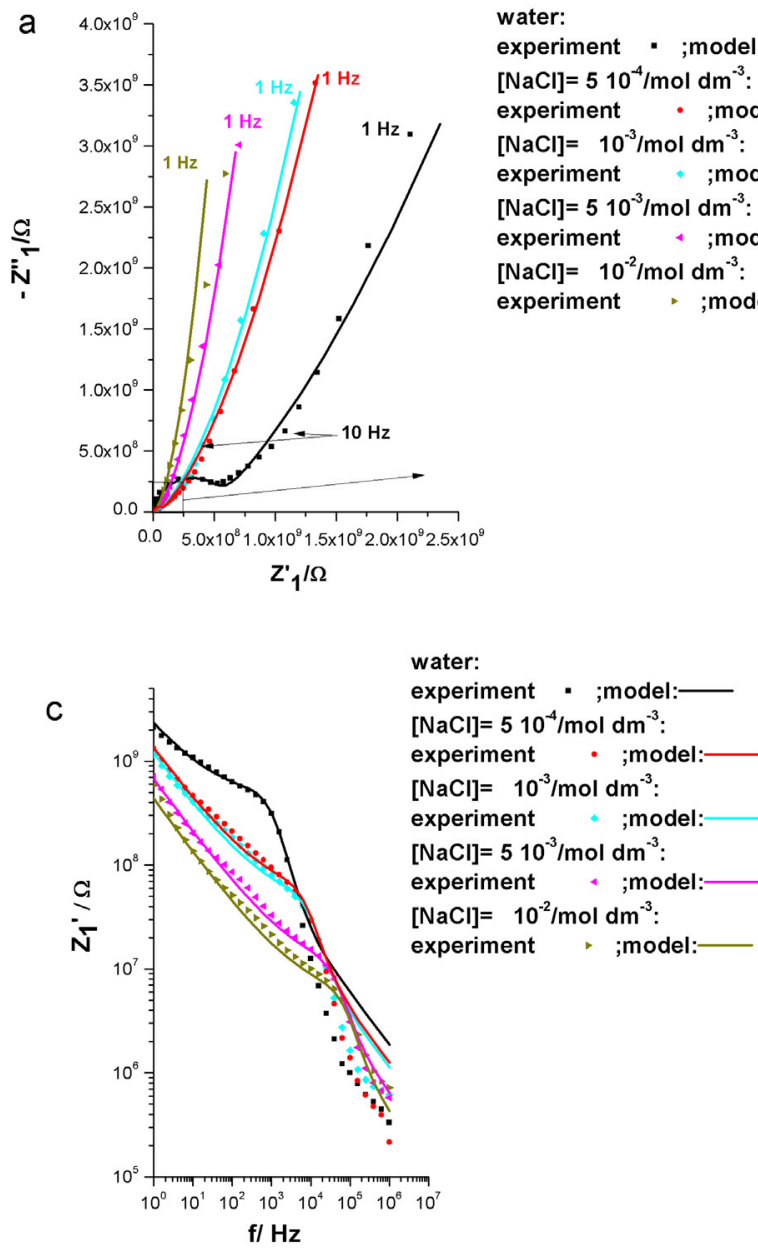

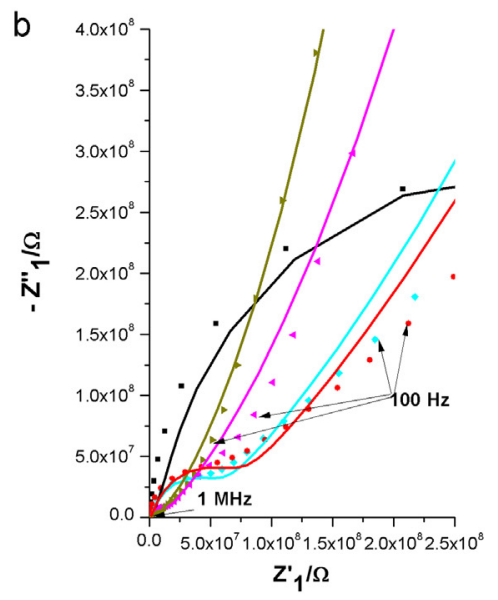

water:

experiment - ;model:$[\mathrm{NaCl}]=510^{-4} / \mathrm{mol} \mathrm{dm}^{-3}$ : experiment $\quad$;model:$[\mathrm{NaCl}]=10^{-3} / \mathrm{mol} \mathrm{dm}^{-3}$ : experiment ;model:$[\mathrm{NaCl}]=510^{-3} / \mathrm{mol} \mathrm{dm}^{-3}$ : experiment 4 ;model:$[\mathrm{NaCl}]=10^{-2} / \mathrm{mol} \mathrm{dm}^{-3}$ : experiment, ;model:-

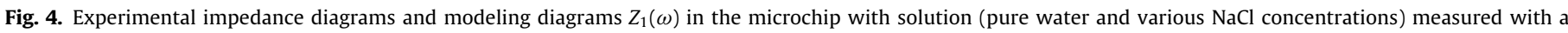

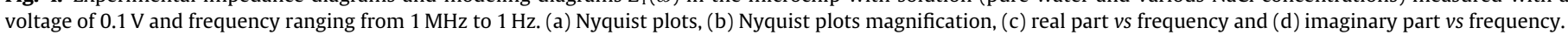

following work, all results will be represented by the impedance $Z_{1}(\omega)$.

\subsection{EIS measurements in microchannel filled with $\mathrm{NaCl}$ solution:}

The global impedance $Z_{G}(\omega)$ between the two microelectrodes, in the case of the microchannel being filled with a solution, depends on the different parts which constitute the microchip. In this configuration, $Z_{\mathrm{G}}(\omega)$ can be expressed as the combination between $Z_{1}(\omega)$ and $Z_{2}(\omega)$ (Eq. (3)):

$\frac{1}{Z_{\mathrm{G}}(\omega)}=\frac{1}{Z_{1}(\omega)}+\frac{1}{Z_{2}(\omega)}$

where $Z_{1}(\omega)$ corresponds to a combination of impedances in the microchannel with the microchannel interface/PET and the impedance of the $5-\mu \mathrm{m}$ thick. The impedance $Z_{1}(\omega)$ is equal to

$Z_{1}(\omega)=2 Z_{1, \operatorname{PET}}(\omega)+\frac{R_{S}}{1+j \omega C_{S} R_{S}}+2 Z_{\text {int }}(\omega)$

In the microchannel: $R_{S}$ with units of $\Omega$ denotes the solution resistance in the microchannel which depends on the solution conductivity and on the geometry of microchannel, and $C_{S}$ in $\mathrm{F}$ represents the solution capacitance, which depends on its relative permittivity, $\varepsilon_{r, \text { solution, }}$ usually equal to water permittivity in the case of a dilute solutions $\left(\varepsilon_{r \text {,water }}=78\right)$. In a typical measuring cell $(d=1 \mathrm{~cm})$, the distance between the two electrodes is large enough to neglect the capacitance of the solution $\left(C_{S}\right)$. However, this is not the case in the present microchip configuration, where the distance between the microelectrodes is only $120 \mu \mathrm{m}$.

In the PET layer of $5 \mu \mathrm{m}$ : the geometric capacitance calculated by Eq. (5) for the PET layer of $5 \mu \mathrm{m}\left(C_{1, \mathrm{PET}}\right)$ is equal to $1.4 \times 10^{-14} \mathrm{~F}$. This capacitance depends on the PET permittivity, PET thickness $\left(d_{1}=5 \times 10^{-6} \mathrm{~m}\right)$, and surface contact area $\left(S_{1}=8 \times 10^{-9} \mathrm{~m}^{2}\right)$, (see in Fig. 1):

$C_{1, \mathrm{PET}}=\frac{\varepsilon_{0} \varepsilon_{r} S_{1}}{d_{1}}$

Taking into account the results obtained in the case of the PET thickness of $120 \mu \mathrm{m}$, the impedance for the PET thickness of $5 \mu \mathrm{m}$ is given by

$Z_{1, \mathrm{PET}}(\omega)=\frac{1}{(j \varepsilon)^{\alpha_{1, \mathrm{PET}}} Q_{1, \mathrm{PET}}}$

where $Q_{1, \text { PET }}$ in $\Omega^{-1} \mathrm{~s}^{\alpha}$ is the modeled capacitive behavior of the PET thickness of $5 \mu \mathrm{m}$ and $\alpha_{1, \mathrm{PET}}$ is the CPE exponent.

At the PET/microchannel interface, the impedance in the $\mathrm{PET} /$ microchannel interface has a CPE behavior given by

$Z_{\text {int }}(\omega)=\frac{1}{(j \omega)^{\alpha_{\text {int }}} Q_{\text {int }}}$

where $Q_{\text {int }}$ is the CPE constant at the interface and $\alpha_{\text {int }}$ is the CPE exponent.

Experimentally, $Z_{1}(\omega)$ is obtained from Eq. (3) where $Z_{2}(\omega)$ is the experimental values of the impedance for an empty microchannel 
and $Z_{G}(\omega)$ is the experimental values of the impedance for a filled microchannel with sodium chloride solution.

The real and imaginary parts of $Z_{1}(\omega)$ are calculated from

$Z_{1}^{\prime}=\frac{\left[\left(Z_{2}^{\prime} Z_{G}^{\prime}-Z_{G}^{\prime \prime} Z_{2}^{\prime \prime}\right)\left(Z_{2}^{\prime} Z_{G}^{\prime}\right)+\left(Z_{2}^{\prime \prime} Z_{G}^{\prime \prime}\right)\left(Z_{2}^{\prime \prime} Z_{G}^{\prime}+Z_{G}^{\prime \prime} Z_{2}^{\prime}\right)\right]}{\left(Z_{2}^{\prime}-Z_{G}^{\prime}\right)^{2}+\left(Z_{2}^{\prime \prime}-Z_{G}^{\prime \prime}\right)^{2}}$

and

$Z_{1}^{\prime \prime}=\frac{\left[\left(Z_{2}^{\prime} Z_{G}^{\prime}+Z_{G}^{\prime \prime} Z_{2}^{\prime \prime}\right)\left(Z_{2}^{\prime}-Z_{G}^{\prime}\right)-\left(Z_{2}^{\prime \prime}-Z_{G}^{\prime \prime}\right)\left(Z_{2}^{\prime \prime} Z_{G}^{\prime}-Z_{G}^{\prime \prime} Z_{2}^{\prime}\right)\right]}{\left(Z_{2}^{\prime}-Z_{G}^{\prime}\right)^{2}+\left(Z_{2}^{\prime \prime}-Z_{G}^{\prime \prime}\right)^{2}}$

where $Z_{\mathrm{G}}^{\prime}, Z_{\mathrm{G}}^{\prime \prime}, Z_{1}^{\prime}, Z_{1}^{\prime \prime}, Z_{2}^{\prime}$ and $Z_{2}^{\prime \prime}$ denote the real and imaginary parts of the impedances $Z_{\mathrm{G}}(\omega), Z_{1}(\omega)$ and $Z_{2}(\omega)$, respectively.

Electrochemical impedance spectroscopy measurements with a voltage of $0.1 \mathrm{~V}$ and frequency ranging from $1 \mathrm{MHz}$ to $1 \mathrm{~Hz}$ were performed for microchannels filled with water and various concentrations of $\mathrm{NaCl}\left(5 \times 10^{-4} \mathrm{M}\right.$ to $\left.10^{-2} \mathrm{M}\right)$. The goal was to extract the values of the solution resistance in the microchannel included in the $Z_{1}(\omega)$ expression by varying the solution conductivity in the microchannel.

The corrected impedance diagrams plotted by eliminating the PET layer impedance (of $120 \mu \mathrm{m}$ ) contribution from the global microdevice response are shown in Fig. 4. Nyquist plots exhibit a loop from very high frequencies to medium frequencies $(1 \mathrm{MHz}-100 \mathrm{~Hz})$ and a capacitive behavior at low frequencies (see Fig. 4a and b). One can observe that the diameter of the loop is inversely related to the microchannel conductivity.

The highest resistance corresponding to the largest diameter loop obtained was recorded in the case of water (water conductivity measured: $3 \mu \mathrm{S} \mathrm{cm}^{-1}$ ); whereas, the lowest value was obtained for the $10^{-2} \mathrm{M} \mathrm{NaCl}$ solution (conductivity measured: $1194 \mu \mathrm{S} \mathrm{cm}^{-1}$ ). This effect is also clearly shown in Fig. 4c. For a frequency range from $10 \mathrm{kHz}$ to $1 \mathrm{~Hz}$, the real part of the measured impedance decreased linearly with the microchannel conductivity.

The evolution of the log-log plot representation of the imaginary part (Fig. 4c) shows that, in the high frequency range from $1 \mathrm{MHz}$ to $50 \mathrm{kHz}$ (filled with $10^{-2} \mathrm{M} \mathrm{NaCl}$ solution) and from $1 \mathrm{MHz}$ to $1 \mathrm{kHz}$ (filled with water), all slopes are estimated to 0.99 , which is close to a pure capacitive behavior. Moreover, the cut-off frequency varies and depends on solution conductivity.

It is important to stress that, at the intermediate frequency ( $5 \mathrm{kHz}-300 \mathrm{~Hz}$ for $\mathrm{NaCl} 10^{-2} \mathrm{M}$ and $1 \mathrm{kHz}-300 \mathrm{~Hz}$ for water), the slope of imaginary part was found equal to 0.5 . This behavior is characteristic of diffusion impedance or of the impedance of a rough interface.

The diffusion impedance analysis could be complicated in case of anomalous behavior [20-23]. But in the present case, the hypothesis of diffusion impedance could be disregarded due to the fact that the microelectrodes were not in contact with electrolyte and the current was not faradaic. It is important to notice that diffusion impedance is a part of faradaic impedance. Only resistivity, permittivity and species adsorption may be considered for the present system, and, as a consequence, only the interfacial impedance of rough surface was used in the impedance analysis. As a proof of that, scanning electron microscopy (SEM) micrographs of the photoablated PET surface presented in Fig. 5 highlight a microstructured surface constituted by the well-known microhills and microvalleys region on the microchannel surface due to photoablation of crystalline and amorphous regions, respectively [24-26]. This observation supports the conclusion that the interfacial impedance including the photoablated PET microchannel should not be represented as a pure capacitance. To take into account this characteristic, the De Levie model [27] for rough surface was used and adapted by different authors [28-30] in order to determine impedance in rough or porous surfaces. In our case, this model could be also adapted for a microstructured surface.
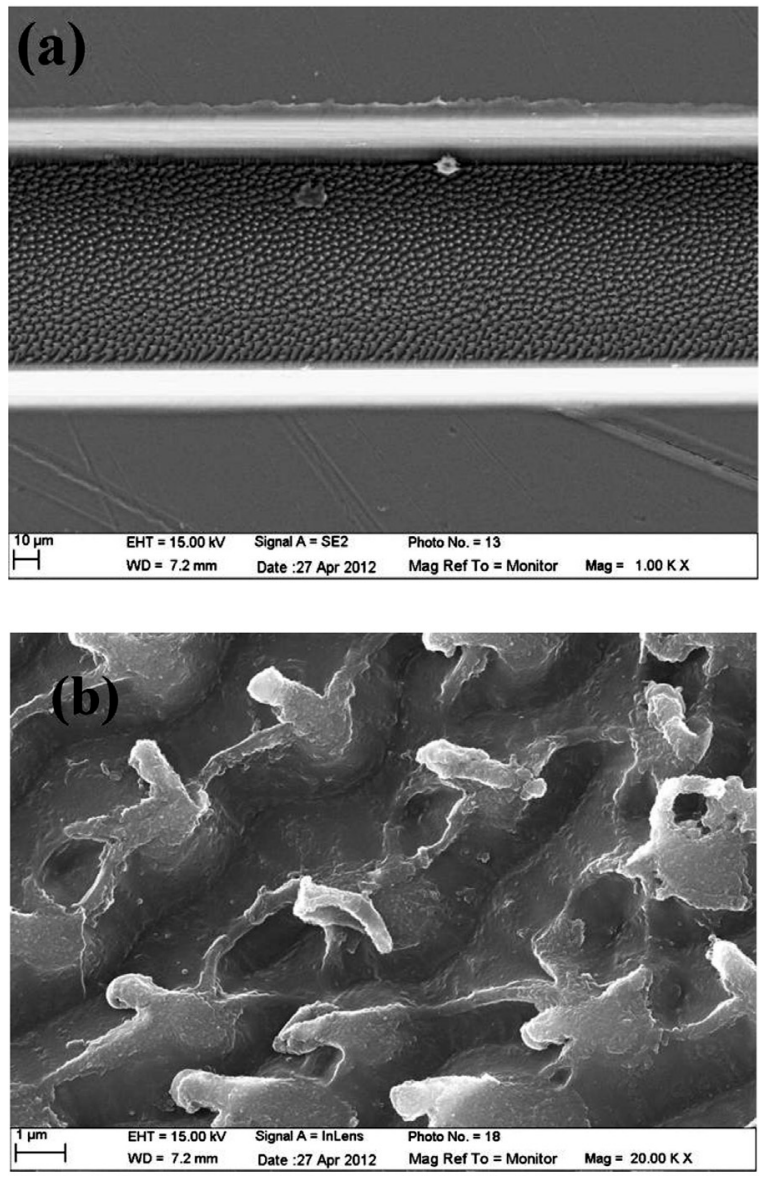

Fig. 5. (a) SEM micrograph of the photoablated PET microchannel. (b) Microstructured aspect of the bottom microchannel.

In order to study the influence of the CPE exponent ( $\alpha$ parameter) and to validate the hypothesis that the De Levie model applies in the present case, the $Z_{1}(\omega)$ impedance model was calculated for different values of the $\alpha_{\mathrm{CPE}}$ parameter. A comparison between the experimental data and $Z_{1}(\omega)$ impedance model is presented in Fig. 6 with the assumed value of $\alpha_{\mathrm{CPE}}$ as a parameter.

The value of $\alpha_{\mathrm{CPE}}$ has a strong influence on the impedance in a frequency range that extends from $1 \mathrm{MHz}$ to $1 \mathrm{~Hz}$ for the imaginary and real parts. The best correspondence between model and experiment was found with $\alpha_{\mathrm{CPE}}=0.5$.

As demonstrated by Keiser et al. [31], for any pore shape, the impedance of a rough surface at high frequencies approaches $45^{\circ}$ in the Nyquist plot (corresponding to a slope of 0.5 in the log-log representation of the imaginary part of the impedance as a function of frequency). The geometry of the microstructured surface is close to the shape numbered 5 in reference [31] and can be seen to be a good approximation for a photoablated microchannel. If the impedance corresponds to the high frequency model in the entire frequency range, its representation is a CPE as in Eq. (7) with $\alpha_{\mathrm{CPE}}=0.5$. This indicates that the CPE element for a photoablated surface microchannel is proportional to the square root of the capacitance of a non photoablated one. Then, we shall have to determine the value of $Q_{i n t}$ for $\mathrm{NaCl}$ at various concentrations.

In the Nyquist diagram, we observed at low frequencies a capacitive branch due to the increase of the imaginary part of the impedance for frequencies lower than $100 \mathrm{~Hz}$. This behavior is influenced by the electrical conductivity of the microchannel solution as displayed in Fig. 4. Referring to the proposed electrical circuit, this behavior defines the interface PET/microchannel. 

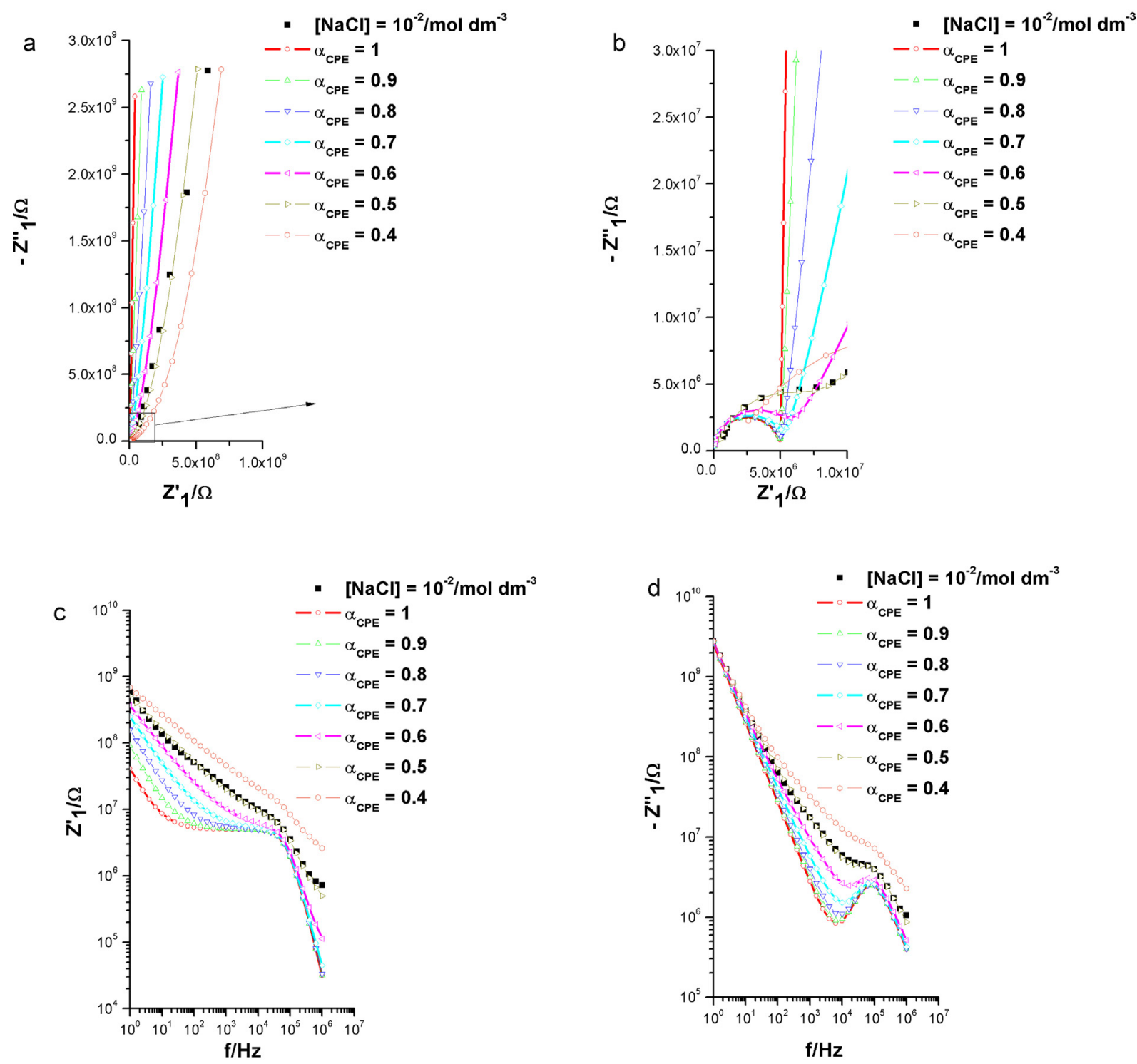

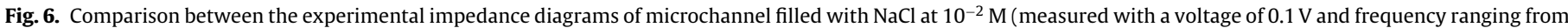
$1 \mathrm{MHz}$ to $1 \mathrm{~Hz}$ ) and the CPE model with $\alpha_{\mathrm{CPE}}$ as a parameter. (a and b) Nyquist plots, (c) real part and (d) imaginary part.

In the knowledge that the PET surface has functional groups that can form electrostatic interactions with ionic species, it is obvious that high concentrations of $\mathrm{NaCl}$ increase the capacitive effect recorded at low frequencies. The use of this impedance model in Eq. (4) provides an excellent fit to the EIS spectra shown in Fig. 4.

A set of fitted parameters are reported in Table 1 . The model provided a very good fit to the experimental data, as was confirmed by different graphical representations of the model and data values.
The values of the CPE element $\left(Q_{1, \mathrm{PET}}\right)$ obtained for water and for a $\mathrm{NaCl}$ solution displayed in Table 1 show a slight difference that can be related to the microchannel composition. Moreover, the fitted value of $Q_{1, \mathrm{PET}}$ is much higher than the geometric capacitance $C_{1, \mathrm{PET}}$. Conversely to the slight difference observed between $Q_{2, \text { PET }}$ and $C_{2, \mathrm{PET}}$, in the case of CPE element $Q_{1, \mathrm{PET}}$, the difference arose from the value of the surface contact area $S_{1}$ which was underestimated, particularly on the side of the microchannel. The estimated value of $C_{1, \text { PET }}$ could be seen as a smaller value due to the fact that only the

Table 1

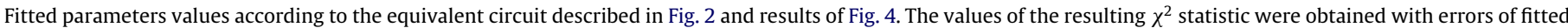
values, $\sigma=0.01$, for frequency ranging from $1 \mathrm{MHz}$ to $1 \mathrm{~Hz}$.

\begin{tabular}{|c|c|c|c|c|c|c|c|c|}
\hline $\mathrm{NaCl}\left(\mathrm{mol} \mathrm{dm}^{-3}\right)$ & $\rho(\Omega \mathrm{cm})$ & $Q_{1, \text { РET }}\left(\Omega^{-1} s^{\alpha}\right)$ & $\alpha_{1, \mathrm{PET}}$ & $R_{S}(\Omega)$ & $C_{S}(\mathrm{~F})$ & $Q_{\text {int }}\left(\Omega^{-1} s^{\alpha}\right)$ & $\alpha_{\text {int }}$ & $\chi^{2}(\%)$ \\
\hline 0 (water) & $3.2 \times 10^{5}$ & $25 \times 10^{-11}$ & & $4.5 \times 10^{8}$ & $3 \times 10^{-13}$ & $0.6 \times 10^{-9}$ & & 4.8 \\
\hline $5 \times 10^{-4}$ & $10^{4}$ & & & $5 \times 10^{7}$ & & $0.9 \times 10^{-9}$ & & 3.4 \\
\hline $10^{-3}$ & $5 \times 10^{3}$ & & 0.99 & $2.5 \times 10^{7}$ & & $1 \times 10^{-9}$ & 0.5 & 3.1 \\
\hline $5 \times 10^{-3}$ & $1.8 \times 10^{3}$ & $14 \times 10^{-11}$ & & $9 \times 10^{6}$ & $4 \times 10^{-13}$ & $1.8 \times 10^{-9}$ & & 2.8 \\
\hline $10^{-2}$ & 840 & & & $5 \times 10^{6}$ & & $2.410^{-9}$ & & 2.6 \\
\hline
\end{tabular}




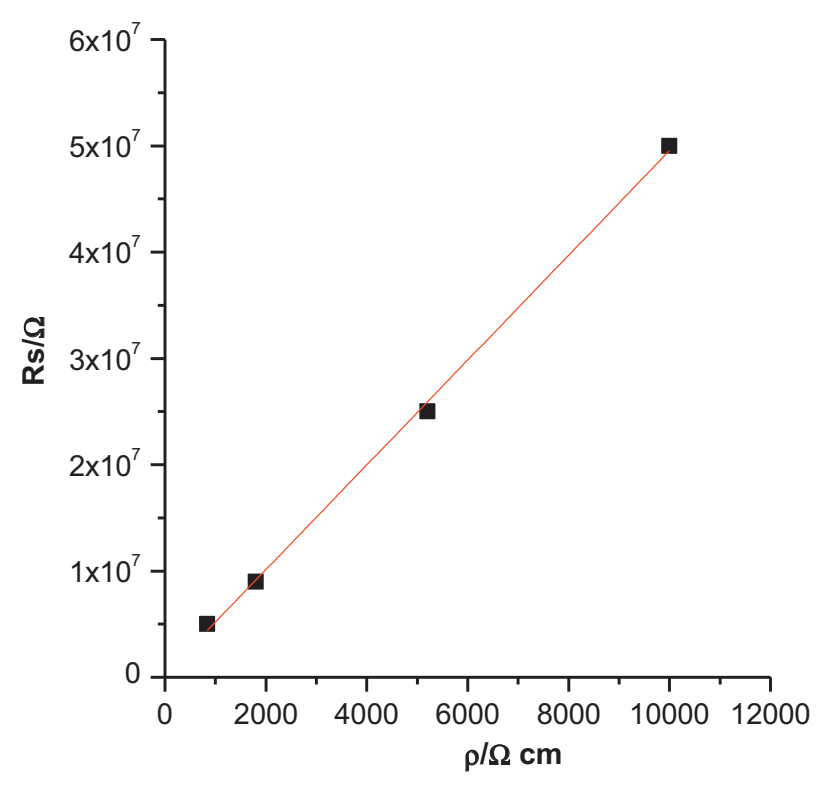

Fig. 7. Plot of loop diameter in Nyquist plot vs solution resistivity.

vertical streamlines from the $S_{1}$ to microchannel section displayed in Fig. 1 were considered.

The $R_{S}$ values obtained with the fitting procedure show that there is a relationship between resistivity and solution resistance, given as

$K=\frac{R_{S}}{\rho}$

where $K$ in $\mathrm{m}^{-1}$ is the cell constant microchannel.

A plot of the solution resistivity, $\rho$, against the length of loop diameter, $R_{S}$, gives rise to straight lines with a slope that is comparable to a cell constant, $K$. The cell constant was found to be equal to $4.93 \times 10^{5} \mathrm{~m}^{-1}$ (see Fig. 7). This latter observation supports the model used in this paper.

\section{Conclusions}

In this study, we have demonstrated that contact-free impedance measurements can be successfully implemented in an insulated polymer for flexible microchips. The impedance technique has the advantage that it can carry out in situ characterization to obtain several physical parameters. Moreover, a new approach involving a new data processing for the analysis of the contactfree impedance through two parallel planar microelectrodes is demonstrated. It is pointed out that the resistivity through the PET layer cannot be neglected and must therefore be taken into account in the global microchip response. Indeed, the photoablated PET surface should be considered to be a microstructured surface, characterized by a constant phase element with a typical exponent of 0.5 . The impedance model proposed here is inspired by the classical equation established by De Levie which leads to accurate and efficient fitting of our experimental data. This study allowed a superior understanding of the global response of the PET microchip impedance. These steps are crucial in order to choose and optimize the experimental conditions for biosensor development in any kind of flexible polymer microchips [32].

\section{Acknowledgments}

We thank Stephan Borensztajn and Françoise Pillier at "Laboratoire Interfaces et Systèmes Electrochimiques-Université Pierre \&
Marie Curie, UPMC Paris 6" for technical assistance on SEM micrographs acquisition. This research was supported by the French research organism "Institut de Recherche pour le développement" (IRD).

\section{References}

[1] J.S. Rossier, A. Schwarz, F. Reymond, R. Ferrigno, F. Bianchi, H.H. Girault, Microchannel networks for electrophoretic separations, Electrophoresis 20 (1999) 727.

[2] J. Yakovleva, R. Davidsson, A. Lobanova, M. Bengtsson, S. Eremin, T. Laurell, J. Emnéus, Microfluidic enzyme immunoassay using silicon microchip with immobilized antibodies and chemiluminescence detection, Analytical Chemistry 74 (2002) 2994.

[3] A. Manz, N. Graber, H.M. Widmer, Miniaturized total chemical analysis systems: a novel concept for chemical sensing, Sensors and Actuators B 1 (1990) 244.

[4] A.E. Guber, M. Heckele, D. Herrmann, A. Muslija, V. Saile, L. Eichhorn, T. Gietzelt, W. Hoffmann, P.C. Hauser, J. Tanyanyiwa, A. Gerlach, N. Gottschlich, G. Knebel, Microfluidic lab-on-a-chip systems based on polymers fabrication and application, Chemical Engineering Journal 101 (2004) 447.

[5] B.J. Cheek, A.B. Steel, M.P. Torres, Y.-Y. Yu, H. Yang, Chemiluminescence detection for hybridization assays on the flow-thru chip, a three-dimensional microchannel biochip, Analytical Chemistry 73 (2001) 5777.

[6] J.R. Epstein, I. Biran, D.R. Walt, Fluorescence-based nucleic acid detection and microarrays, Analytica Chimica Acta 469 (2002) 3.

[7] K. Dill, D.D. Montgomery, A.L. Ghindilis, K.R. Schwarzkopf, Immunoassays and sequence-specific DNA detection on a microchip using enzyme amplified electrochemical detection, Journal of Biochemical and Biophysical Methods 59 (2004) 181.

[8] K. Dill, A. Ghindilis, in: K. Microarrays, R. Dill, P. Liu, Grodzinski (Eds.), Electrochemical Detection on Microarrays, Springer, New York, 2009, p. 25.

[9] R.S. Martin, K.L. Ratzlaff, B.H. Huynh, S.M. Lunte, In-channel electrochemical detection for microchip capillary electrophoresis using an electrically isolated potentiostat, Analytical Chemistry 74 (2002) 1136.

[10] J. Gamby, J.-P. Abid, H.H. Girault, Supercapacitive admittance tomoscopy, Journal of the American Chemical Society 127 (2005) 13300.

[11] E. Kjeang, B. Roesch, J. McKechnie, D. Harrington, N. Djilali, D. Sinton, Integrated electrochemical velocimetry for microfluidic devices, Microfluid Nanofluid 3 (2007) 403.

[12] O. Ordeig, N. Godino, J. del Campo, F.X. Muñoz, F. Nikolajeff, L. Nyholm, On-chip electric field driven electrochemical detection using a poly(dimethylsiloxane) microchannel with gold microband electrodes, Analytical Chemistry 80 (2008) 3622.

[13] J. Gamby, J.-P. Abid, B. Tribollet, H.H. Girault, Nanomosaic network for the detection of proteins without direct electrical contact, Small 4 (2008) 802.

[14] G.M. Dittami, H.E. Ayliffe, C.S. King, R.D. Rabbitt, A multilayer MEMS platform for single-cell electric impedance spectroscopy and electrochemical analysis, Journal of Microelectronic Systems 17 (2008) 850

[15] T. Sun, E.J. Swindle, J.E. Collins, J.A. Holloway, D.E. Davies, H. Morgan, On-chip epithelial barrier function assays using electrical impedance spectroscopy, Lab Chip 10 (2010) 1611.

[16] A.V. Jagtiani, J. Zhe, High throughput microfluidic electrical impedance flow cytometry for assay of micro particles, Micro and Nanosystems 2 (2010) 298.

[17] A.J. Zemann, E. Schnell, D. Volgger, G.K. Bonn, Contactless conductivity detection for capillary electrophoresis, Analytical Chemistry 70 (1998) 563.

[18] G. Schaumburg, On the accuracy of dielectric measurements, Dielectrics Newsletter 8 (1997) 5.

[19] M.E. Orazem, N. Pébère, B. Tribollet, Enhanced graphical representation of electrochemical impedance data, Journal of Electrochemical Society 153 (4) (2006) 129.

[20] R. Kumar, R. Kant, Theory of generalized Gerischer admittance of realistic fractal electrode, Journal of Physical Chemistry C 113 (2009) 19558.

[21] S. Sunde, I.A. Lervik, M. Tsypkin, L.-E. Owe, Impedance analysis of nanostructured iridium oxide electrocatalysts, Electrochimica Acta 55 (2010) 7751.

[22] F. Batalioto, A.R. Duarte, G. Barbero, A.M.F. Neto, Dielectric dispersion of water in the frequency range from $10 \mathrm{MHz}$ to $30 \mathrm{MHz}$, Journal of Physical Chemistry B $114(2010) 3467$.

[23] E.K. Lenzi, P.R.G. Fernandes, T. Petrucci, H. Mukai, H.V. Ribeiro, Anomalousdiffusion approach applied to the electrical response of water, Physical Reviews E 84 (2011) 041128.

[24] T. Lippert, J.T. Dickinson, Chemical and spectroscopic aspects of polymer ablation: special features and novel directions, Chemical Reviews 103 (2003) 453.

[25] J. Gamby, M. Lazerges, C. Pernelle, H. Perrot, H.H. Girault, B. Tribollet, Electroacoustic miniaturized DNA-biosensor, Lab Chip 7 (2007) 1607.

[26] J. Gamby, M. Lazerges, H.H. Girault, C. Deslouis, C. Gabrielli, H. Perrot, B. Tribollet, Electroacoustic polymer microchip as an alternative to quartz crystal microbalance for biosensor development, Analytical Chemistry 80 (2008) 8900.

[27] R. De Levie, Advances in electrochemistry and electrochemical engineering, in: P. Delahay (Ed.), Interscience, VI, John Wiley and Sons, New York, 1967, p. 329.

[28] O.E. Barcia, E. D’Elia, I. Frateur, O.R. Mattos, N. Pébère, B. Tribollet, Application of the impedance model of de Levie for the characterization of porous electrodes, Electrochimica Acta 47 (2002) 2109. 
[29] J.-P. Candy, P. Fouilloux, M. Keddam, H. Takenouti, The characterization of porous electrodes by impedance measurements, Electrochimica Acta 26 (1981) 1029.

[30] P. Fievet, M. Mullet, J. Pagetti, Impedance measurements for determination of pore texture of a carbon membrane, Journal of Membrane Science 149 (1998) 143.
[31] H. Keiser, K.D. Beccu, M.A. Gutjahr, Abschätzung der porenstruktur poröser elektroden aus impedanzmessungen, Electrochimica Acta 21 (1976) 539.

[32] S. Miserere, G. Mottet, V. Taniga, S. Descroix, J.-L. Viovy, L. Malaquin, Fabrication of thermoplastics chips through lamination based techniques, Lab Chip 12 (2012) 1849 